\title{
Role of Sonohysterography in Evaluatingthe Spectrum of Endometrial Pathologies
}

\author{
*SureendharMohan ${ }^{1}$,Dhivya Sri $^{2}{ }^{2}$,Paarthipan Natarajan ${ }^{3}$, Kiran Gottumukkala ${ }^{4}$ \\ ,Rajasekhar K.V. ${ }^{5}$ \\ ${ }^{I}$ Assistant Professor, Department of radiodiagnosisMeenakshi Medical college Hospital and Research \\ Institute(MMCH \& RI), Kanchipuram \\ ${ }^{2}$ Post graduate, Department of radiodiagnosis, Meenakshi Medical college Hospital and Research \\ Institute(MMCH \& RI), Kanchipuram. \\ ${ }^{3}$ Professor, Department of radiodiagnosis, Meenakshi Medical college Hospital and Research \\ Institute (MMCH \& RI), Kanchipuram \\ ${ }^{4}$ Post graduate, Department of radiodiagnosis, Meenakshi Medical college Hospital and Research \\ Institute(MMCH \& RI), Kanchipuram. \\ ${ }^{5}$ Professor and Head, Department of radiodiagnosisMeenakshi Medical college Hospital and Research \\ Institute(MMCH \& RI), Kanchipuram.
}

\begin{abstract}
Aim: To evaluate the endometrial pathologies with saline infusion sonohysterography, where ultrasound showed nonspecific endometrial thickening.

Proposed Materials And Methods: We studied 50 perimenopausal patients with non specific endometrial thickening on transvaginal ultrasound using saline infusion sonohysterography. A GE pro5 ultrasound machine was used with high resolution $7.5 \mathrm{MHZ}$ transvaginal probe. Baseline transvaginal sonography was performed and endometrial findings were recorded. Then under strict ascetic precautions, under ultrasound guidance a $5 F$ canal was introduced upto mid cavity level and 10 to $20 \mathrm{ml}$ of saline infused.The endometrial findings were recorded again.

Discussion: It is very difficult to clearly delineate pathologies such as focal endometrial hyperplasia, polyp, submucosal fibroids, endometritis, endometrial adhesions and endometrial malignancies and to distinguish these from one another on a transvaginal sonography. Most of them appears as non specific diffuse focal endometrial thickening. By infusing saline and distending the cavity. We depict the pathologies more clearly and increase our diagnostic accuracy. In a premenopausal patient the diagnosis of an abnormally thickened endometrium is dependent on the phase of the menstrual cycle.In general a thickness greater than 8mm during the proliferative phase or greater than $16 \mathrm{~mm}$ during the secretory phase is considered abnormal . The examination is best performed on the day 4, 5 or 6 of the menstrual cycle when the diameter of the endometrium should be thinnest.
\end{abstract}

\section{Introduction}

Abnormal Uterine Bleeding (AUB ) may be defined as any variation from thenormal menstrual cycle, and includes changes in regularity and frequency of menses,in duration of flow, or in amount of blood loss. Abnormal uterine bleeding iscommon but complicated clinical presentation, because diagnosis is difficult as thecause may be from simple as DUB to complicated as endometrial carcinoma.

Endometrial abnormalities such as endometrial polyp, sub mucous myomas are themost common cause of abnormal uterine bleeding (AUB).

Transvaginal Sonography (TVS) is the standard imaging technique for theprimary investigation for endometrial abnormalities in the case of AUB. Thistechnique is effective in evaluating endometrial abnormalities in postmenopausalwomen caused by atrophy. But it is difficult to delineate the thickened andinhomogeneous endometrium and it has low specificity and limitations which canovercome by saline infused sonohysterography.Dilatation and curettage (D\&C) previously was the common method fordiagnosing endometrial abnormalities in women with abnormal uterine bleeding. Incurettage procedures where less than half the uterine cavity is curetted, affect thesensitivity of D \& C.Hysteroscopy findings with endometrial biopsy is superior to curettage alonein effective diagnosis of endometrial abnormalities. But this procedure needs greaterskills and expertise to reach the patient. Both D\&C and hysteroscopy (HS) areinvasive procedures can be done under general anaesthesia and with considerablecost. Both saline infused sonohysterography (SIS) \& HS needs histologicalconfirmation. HS can take biopsy using miniature forceps. In SIS biopsy can be madeby using the same catheter used for saline infusion. 
Bernard et al reportedinadequate specimens for biopsy during SIS.

Saline infused Sonohysterography is an advanced method where saline isused as contrast medium to clearly visualise the pathology. It has been shown to besafe, simple and effective method for evaluating endometrial pathology usingtransvaginal ultrasound in an outpatient setting. SIS can accurately differentiate focallesions such as polyps and sub mucous myomas from diffuse lesions such ashyperplasia and cancer. If it is a diffuse lesion then endometrial histology gives morerelevant information from which appropriate treatment is possible.An abnormally thick, irregular or indistinct endometrium is often seen atpelvic ultrasound. The differential diagnosis includes diffuse endometrial thickeninglike endometrial hyperplasia, the secretory phase of the menstrual cycle and focaldiseases like endometrial polyps, carcinoma and to differentiate the subendometrialpathology like submucosal leiomyoma and adenomyosis.

The technique of sonohysterography and the results of patients withperimenopausal bleeding who underwent saline infusion sonohysterography arediscussed. The aim is early detection of endometrial cancer in women over fortyyears and to identify pathology, in women below 40 years for effective treatment.

It's an inexpensive, non invasive and convenient method to visualise theuterine cavity, conventional endovaginal ultrasonography especially in evaluatingPremenopausal and postmenopausal patients with abnormal uterine bleeding, as thethick endometrium is mistaken for a physiological state. It is very useful in surgical\& medical management of patients. It is also helpful in determining the appropriatesite for the biopsy.This contrast enhancement with saline has increased diagnostic accuracy.Infusion of saline into the endometrial cavity through a catheter into the endometrialcavity causes distension by separation of cavity walls and by clearly delineating theunderlying disease.

In 1991 Klug 5 described ultrasound of the uterine cavity after instillation ofgel. Then, many authors have reported on the success of saline infusion Sonographyin detecting intra uterine abnormalities, such as polyps and sub mucous myomas.

Diagnostic accuracy of sonohysterography is superior to that of transvaginalultrasound and has a sensitivity of $95 \%$ and a specificity of $88 \%$, according to ameta-analysis in 2003 .

Sonohysterography can be done in any setting as endovaginalultrasonography (US) is performed and the patient preparation is similar to that usedfor radiologic Hysterosalpingography. It can be performed during the first phase ofthe cycle especially when the indication is sterility or thickened endometrium attransvaginal sonography. Sonohysterography is superior to Hysterosalpingography,hysteroscopy, MRI in evaluating the uterine pathology in abnormal uterine bleeding.

Disadvantages of Hysterosalpingography are irradiation and iodinatedcontrast material. It is expensive and provides indirect information about the uterinecavity. One can delineate fibroids and polyps but cannot comment on endometrialthickness.Hysteroscopy can be helpful in visualising the cavity but it cannot determinethe extent of sub mucous myomas and endometrial thickness.MRI is an expensivemodality provides excellent images of the uterus and myometrial pathologydisrupting the endometrium; however, intracavitary lesions are not well demonstratedas compared to SIS.

Advantages of saline infusion sonohysterography:

1. Improved sensitivity /specificity in the detection of pathology.

2. Cost effectives, avoidance of radiation and patient comfort.

3. It assists in determining the diagnosis or therapeutic approach.

4. It may also reduces or eliminate the need for surgical intervention.

\section{Aim And Objectives}

- To evaluate the peri-menopausal and post-menopausal women withabnormal uterine bleeding whose abdominal ultrasound showingendometrial thickening of more than $8 \mathrm{~mm}$ during proliferative phase orgreater than $16 \mathrm{~mm}$ during the secretory phase.

- To assess the role of sonohysterography in clearly delineatingpathologies such as focal hyperplasia, polyps, submucosal fibroids, endometritis, endometrial adhesion and endometrial malignancies.

- To correlate with the histopathological results byhysterectomy,hysteroscopy biopsy.

\section{Uterine pathology:}

\section{Leiomyoma or fibroid:}

Most common,usuallyasymptomatic,if symptomatic usually present withabnormal vaginal bleeding. classified in to 3 types depending on the locationIntramural - Confined to myometriumSubmucosal - Projecting into the uterine cavitySubserosal - Projecting from peritoneal surfaceLeiomyoma has variable appearance in sonography.they are mostly hypo echoic orheterogeneous echo texture.

Fibroids can usually differentiated from polyps or other endometrial abnormalitiesby or shadowing. 


\section{Endometrial polyp:}

It is a common benign lesion and common cause of abnormal vaginalbleeding. It appears as solitary or pedunculated. In TVS polyp appears as echogenichomogeneous texture and cystic areas can be found representing haemorrhage andinfraction. Histologically representing dilated glands. Usually polyp appears as focalthickening of endometrium. Polyp can be identified most easy when the fluid is in theendometrial cavity so SHG is the ideal technique for demonstrating polyp. Polyp andsubmucosal fibroids can be differentiated by seeing the normal endometrium aroundthe fibroid. Colour doppler US shows pedicle artery sign.

\section{Endometrial carcinoma:}

It is most common malignancy in north america.The most common clinicalpresentation is abnormal uterine bleeding. $10 \%$ of women with postmenopausalbleeding will have endometrial CA. There is strong association with oestrogentherapy in postmenopausal women and anovulatory cycles in premenopausal women.The risk factors include age, obesity, diabetes, hypertension \& low parity, polycysticovary syndrome.

$80 \%$ of the endometrial CA are adenocaricoma and others include serous cellCA \& clear cell CA. Sonographically thickened endometrium appears as welldefined,uniformly echogenic and indistinguishable from hyperplasia and polyp.It canalso be seen as inhomogeneous focal mass. A recent studies reported that uterus ispoorly distensible in CA. This is the potential sign of malignancy.

\section{Endometrial hyperplasia:}

Endometrial Hyperplasia is defined as proliferative glands of irregular size \&shape with increase in gland /stromal ratio. Hyperplasia develops from unopposedoestrogen stimulation in postmenopausal and perimenopausal women. It is the causeof PMB in 4-8\% of patients. It is divided into 2 types.1.hyperplasia with cellularatypic 2. Hyperplasia without cellular hyperplasia and further divided into simpleand complex. In atypical hyperplasia there are chances of $23 \%$ for malignancies. InUSG, endometrium is usually thick and echogenic with well defined margins. It canbe focal or asymmetrical.

In a study by

Jorizzo et alon endometrial hyperplasia, cysts were seen in $57 \%$ of patients and endometrial polyps were found in $26 \%$.TVS \& SIS cannotdistinguish the different types of hyperplasia. In addition the thickening ofendometrium that occurs in the secretory and late proliferative phase of the menstrualcycle cannot be distinguished from diffuse thickening of endometrial hyperplasia.

\section{Endometrial atrophy:}

Atrophy of the endometrium is often a physiological postmenopausalphenomenon where it is more specifically termed as postmenopausal endometrialatrophy. While most patients are asymptomatic, it is one of the commonest cause ofpostmenopausal bleeding, accounting for approximately $60-75 \%$ of cases. Often theatrophic endometrium is associated with cystic dilatation of glands where it is thentermed as endometrial cystic atrophy.

Other factors that can cause endometrial atrophy include

- Prolonged oral contraception.

- Hypo-oestrogenic state: ovarian dysfunction.

- Tamoxifen use.

\section{Ultrasound}

The endometrial thickness should measure:

$\bullet<4-5 \mathrm{~mm}$ on a transvaginal ultrasound scan

The uterine body to cervix ratio will also tend to decrease and may approach 1:1.

\section{Uterine adhesions:}

On conventional transvaginal sonography, a subtle irregularity of theendometrial lining in the proliferative phase suggests that an adhesion may bepresent. When the uterine cavity is distended with fluid, synechia are moreeasily detected. Adhesions are described as filmy or dense. In addition, theextent of cavity involvement should be recorded. Saline infusionsonohysterography has a $75 \%$ sensitivity and $93 \%$ specificity for the detectionof uterine adhesions.Both methods had a sensitivity and the specificity of $93 \%$ and $95 \%$,respectively. In contrast, TVS did not detect any of the cases of intrauterineadhesions.

\section{Adenomyoma:}

An adenomyoma is a focal region of adenomyosis resulting in a mass, which isdifficult to distinguish from a uterine fibroid, although in general the degree to whichthe contour of the uterus is distorted is less marked in adenomyosis . The 'mass' ispoorly defined and blends with the surrounding myometrium. Uterine fibroids onthe other hand often have a pseudo capsule of compressed myometrial tissuesurrounding them. 


\section{Materials And Methods}

A prospective study of 50 patients of age between 40-80 yrs who came toObstetrics \& gynaecology department, Meenakshi Medical College, Hospital,Kanchipuram between June 2013 \& May 2015 with complaints of menorrhagia,continuous bleeding PV, metororrhagia, polymenorrhea. The study was startedafter taking prior clearance and permission from the ethical committee andinformed consent from patient.After taking thorough history and detailed clinical examination whoseendometrial thickness was $>8 \mathrm{~mm}$ in USG were subjected to SIS. ALOKA-SSD4000 equipped with $7.5 \mathrm{MHZ}$ transvaginal probe was used. The procedure wasdone and findings were recorded. The samples were then sent to HPE to correlatethe findings with our SIS findings.

Prior to SIS we did transabdominal USG for patients with clinicalsymptoms of menorrhagia metrorrhagiapolymenorrhea or any continuousbleeding PV and endometrial thickness were assessed and those whoseendometrial thickness of $>8 \mathrm{~mm}$ were taken in this study.

\section{Techniques of SIS:}

1. All our patients were priorly informed about the whole procedure and writtenconsent was obtained from them.

2. All our patients were given analgesic before the procedure.

3. Under aseptic precautions patients were made to lye in lithotomy position.

4. With the tenaculum forceps the anterior lip of cervix is holded and then thetransvaginal probe was inserted.

5. Catheter was passed through the endometrial canal and $10-20 \mathrm{ml}$ of saline infused.

6. The endometrial cavity was distended and findings were clearly shown.

7. Then complete sonographic analysis was done in both coronal and sagittalplane and complete evaluation done and the findings were noted.

8. The samples for HPE were sent from OBS \& GYN Department from the hystrectomy or hysterocospy samples.

\section{Diagnostic criteria:}

Polyp:

- Appears as echogenic homogeneous texture and cystic areas can befound representing haemorrhage and infraction.

- Polyp and submucosal fibroids can be differentiated by seeing thenormal endometrium around the fibroid. Colour doppler US showspedicle artery sign.

\section{Fibroid:}

- They are mostly hypo echoic or heterogeneous echo texture.

- Fibroids can usually differentiated from polyps or other endometrialabnormalities by Sacoustic attenuation or shadowing.

Carcinoma:

- Thickened endometrium appears as well defined, uniformly echogenicand indistinguishable from hyperplasia and polyp.

- It can also be seen as inhomogeneous focal mass.

Hyperplasia:

- Endometrium is usually thick and echogenic with well defined margins.

Adenomyosis:

- It appears as hyperechoic sub endometrial linear striations.

\section{Inculsion criteria:}

1. Peri-menopausal \&post menopausal women with unexplained vaginalbleeding.

2. Endometrial thickness of more than $8 \mathrm{~mm}$ in proliferative phase and $16 \mathrm{mmin}$ secretory phase in USG.

\section{Exclusion criteria:}

1. pelvic inflammatory diseases

2. menstrual cycles

3. intra uterine contraceptives like copper T

4. patient not willing to have the diagnostic procedure

5. pregnancy 


\section{Results And Analysis}

In this study 50 patient of perimenopausal and post menopausal women with abnormal uterine bleeding who were full filling the inclusion and exclusion criteria are taken. $29 \%$ of premenopausal women included in the study and $21 \%$ of the post menopausal women were included in the study. The most presenting complaints was abnormal uterine bleeding.In this study most common findings found was fibroids of $36 \%$ in SIS. and the next common is polyp was $14 \%$ and endometrial carcinoma of $4 \%$ and hyperplasia $14 \%$ and adenomyoma of $2 \%$. And out of 50 cases, in 2 cases endometrial cavity could not able to distended with saline due to adhesions and cervical stenosis. This procedure was well tolerated by the patients without any complications. $2 \%$ of the patient had minimal bleeding during the procedure. And few of the patient were complaining of tolerable pain. Nearly 39 cases were was sent to histopathological examination. Out of 50 cases in our study 7 cases were found to normal and 2 other cases we could not able to distend the cavity so nearly 39 cases were compared with HPE. In that, 2 cases does not correlate with our findings

\section{Age Distribution Among 50 Patients With Uterinepathology}

\begin{tabular}{|c|c|c|}
\hline AGE GROUP & FREQUENCY & PERCENT \\
\hline $40-49$ & 7 & $14 \%$ \\
$50-59$ & 22 & $44 \%$ \\
$60-69$ & 18 & $36 \%$ \\
$70-79$ & 2 & $4 \%$ \\
\hline ABOVE 80 & 1 & $2 \%$ \\
\hline
\end{tabular}

Table No 1. Showing frequency of age distribution of patients with uterine pathology

Incidence of age group in our study:

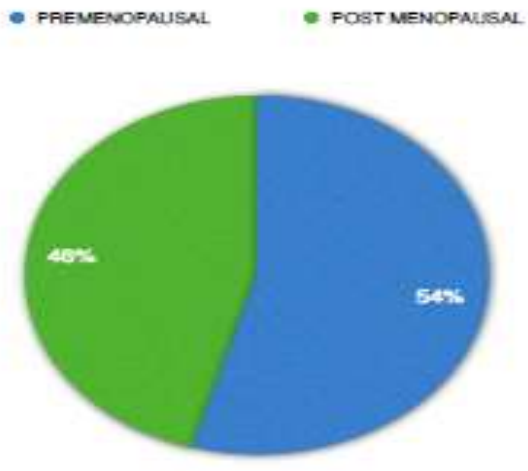

Chart No 2. Distribution of patient in two groups with Premenopausal and post menopausal Incidence of Various Uterine Pathologies in AUB

\begin{tabular}{|c|c|c|c|c|}
\hline Patboloejsal Conditioes & $\begin{array}{c}\text { Pre } \\
\text { mowopautal } \\
\text { Woinen }\end{array}$ & 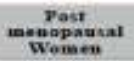 & Total & Percent \\
\hline \multicolumn{5}{|l|}{ Fodumetrial } \\
\hline \multicolumn{5}{|l|}{ Focal } \\
\hline Folyps & 4 & , & J & $14 \%$ \\
\hline Carciesman & . & 2 & 2 & 45 \\
\hline \multicolumn{5}{|l|}{ Diffuse } \\
\hline Ityperplaza & 4 & 1 & 7 & $1+\%$ \\
\hline Secretary & 2 & - & 3 & $4 \%$ \\
\hline \multicolumn{5}{|l|}{ Both } \\
\hline Hyperplata \& Folyps & , & 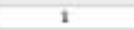 & 4 & $=56$ \\
\hline \multicolumn{5}{|l|}{ Subbenduauefirial } \\
\hline Fibreids & 12 & 6 & 18 & $36 \%$ \\
\hline Ademonyoma & 1 & - & 1 & $2 \%$ \\
\hline \multicolumn{5}{|l|}{$\begin{array}{l}\text { Canid ant dititrued the } \\
\text { caving }\end{array}$} \\
\hline Adteretoes: & 2 & - & 1 & 35 \\
\hline Cervical Stenash & 1 & - & 1 & $2 \%$ \\
\hline $\begin{array}{l}\text { No obvious pathology } \\
\text { found }\end{array}$ & 3 & 4 & ? & $14 \%$ \\
\hline Total cases & 29 & 21 & 50 & $100 \%$ \\
\hline
\end{tabular}

Table No 2. shows Incidence of Various Uterine Pathologies in AUB out of whichhighest incidence was Fibroids with $36 \%$ followed by Polyps \& Hyperplasia with 14\%,Both Hyperplasia and Polyps with 14\%, 
Carcinoma with $4 \%$, Secretory with $4 \%$,Adenomyoma with $2 \%$, adhesions with $2 \%$ and Cervical Stenosis with $2 \%$ were seen inour study.

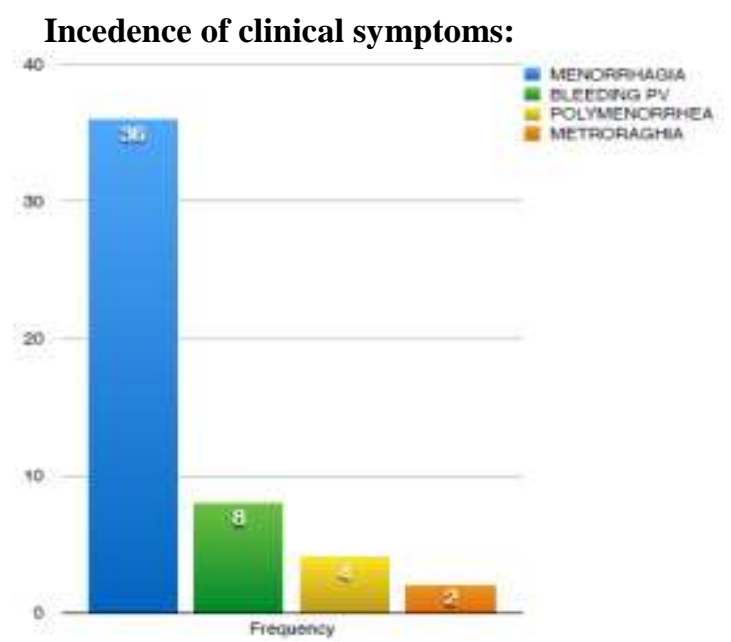

Chart No 4. Frequency of Clinical Symptoms in Uterine Pathology

Incendence of hpe report findings:

\begin{tabular}{|l|c|c|}
\hline HIPE REPORT & NO OF CASES & FREQUENCY \\
\hline POLYP & 6 & $12 \%$ \\
\hline FIBROID & 17 & $24 \%$ \\
\hline HYPERPLASIA & 7 & $14 \%$ \\
\hline ADENOMYOSIS & 1 & $2 \%$ \\
\hline SECRETORY & 2 & $4 \%$ \\
\hline HYPERPLASLA AND POLYP & 4 & $8 \%$ \\
\hline
\end{tabular}

Table No 4. Showing HPE Findings

Incidence of Various Uterine Pathologies in AUB

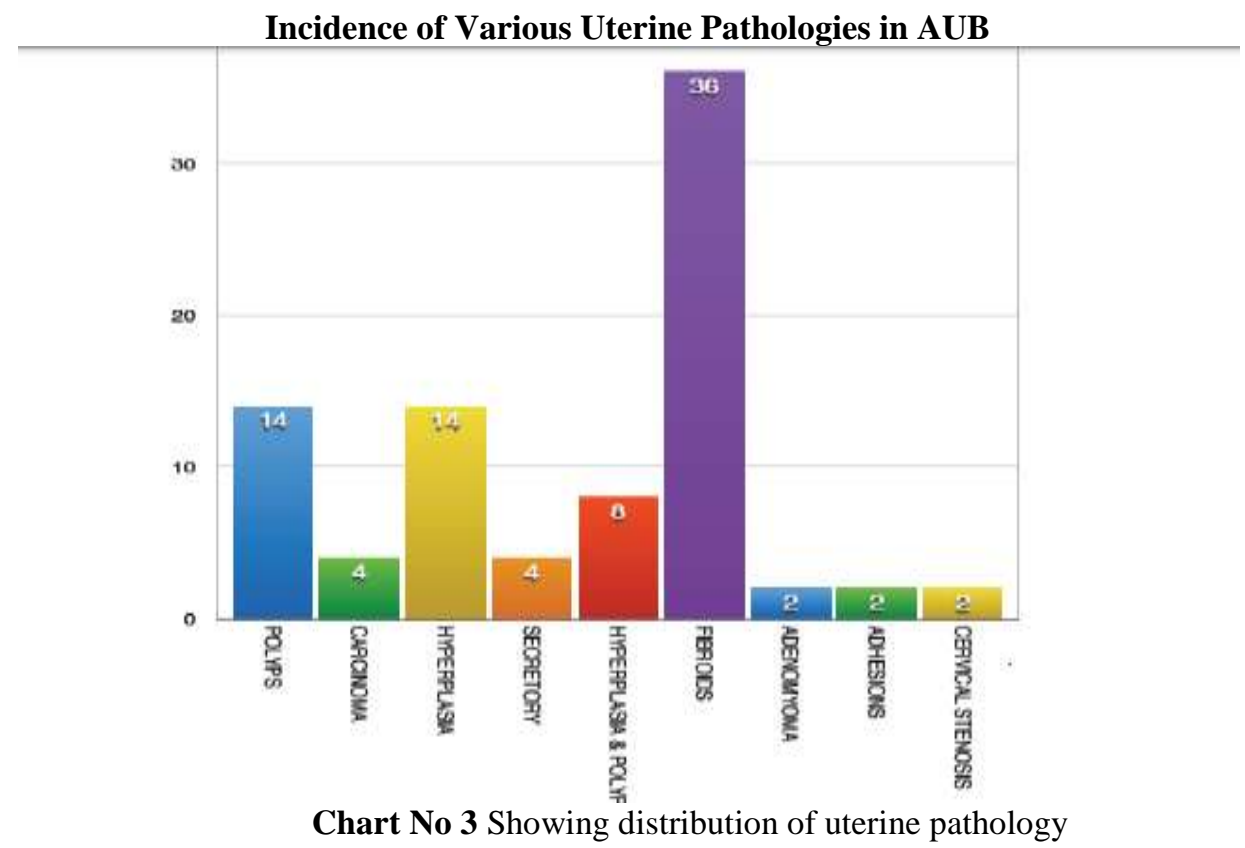




\begin{tabular}{|c|c|c|c|c|}
\hline PATHOLOGX & $\begin{array}{l}\text { SIS } \\
\text { FINDING }\end{array}$ & $\begin{array}{c}\text { HPE } \\
\text { POSIIIVE }\end{array}$ & $\begin{array}{c}\text { HPE } \\
\text { NEGATIVE }\end{array}$ & $\begin{array}{l}\text { HPE NOT } \\
\text { DONE }\end{array}$ \\
\hline FIBROID & 18 & 17 & 1 & $=$ \\
\hline POLYP & 7 & 6 & 1 & - \\
\hline CARCINOMA & 2 & 2 & - & - \\
\hline HYPERPLASLA & 7 & 7 & - & - \\
\hline SECRETORX PHASE & 2 & 2 & - & - \\
\hline ADENOMYOSIS & 1 & 1 & - & - \\
\hline HXPERPLASIAAND POLYP & 4 & 4 & - & - \\
\hline NORMLAL & 7 & - & - & 7 \\
\hline COULD NOT DISTEND & 2 & $=$ & - & - \\
\hline TOTAI & so & 39 & 2 & 7 \\
\hline
\end{tabular}

Table No 5. Correlating our Findings with HPE

Risk factors in aub:

\begin{tabular}{|l|c|c|}
\hline RISK FACTORS & FREQUENCY & PERCENTAGE \\
\hline HO CONTRACEPTIVES & 5 & $10 \%$ \\
\hline OBESITY & 18 & $36 \%$ \\
\hline DIBETUS MELTTUS & 22 & $44 \%$ \\
\hline $\begin{array}{l}\text { HORMONAL REPLACEMENT } \\
\text { THERAPY }\end{array}$ & 5 & $10 \%$ \\
\hline \begin{tabular}{l} 
TOTAL \\
\hline
\end{tabular} & 50 & $100 \%$ \\
\hline
\end{tabular}

Table No 6. Risk Factors in AUB

Risk factors in aub:

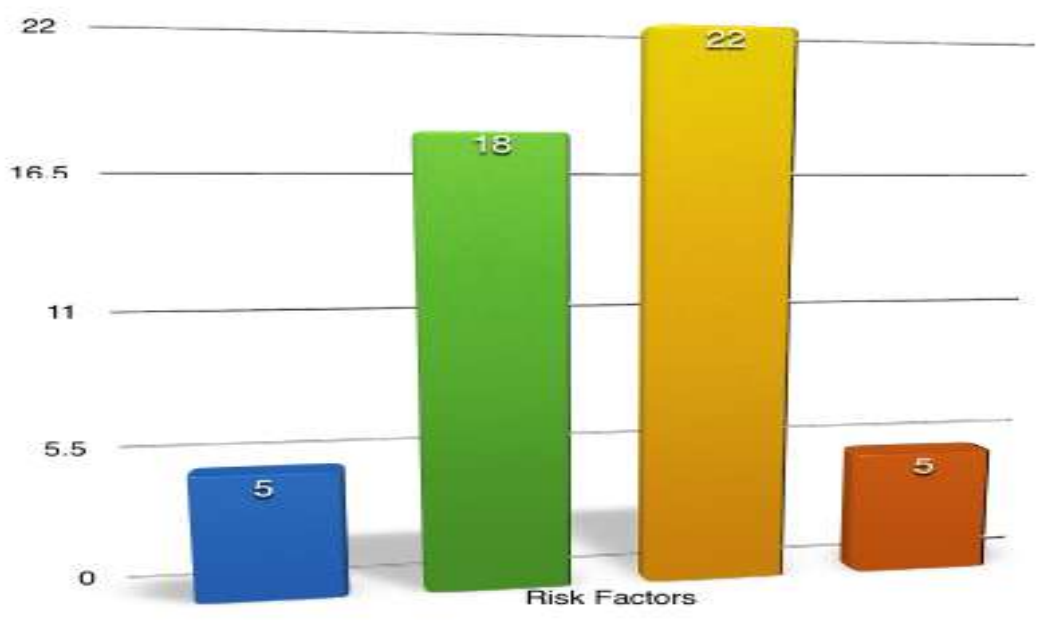

H/O Controceptives

- Obesity

Diabetes Melitus

Hormonal Replacement Therapy

Chart No 5. Risk Factors in AUB 


\section{Discussion}

In the last few decades due to advancement in the diagnostic imaging and ultrasonography is also in front step with the development of newer equipment. TVS is considered as safe, easily accessible as non invasive technique in evaluating endometrial cavity due to the proximity of endovaginal probe to the endometrium. sensitivity of TVS can be increased by instillation of fluid into uterine cavity. TVSoften produces equivocal results but it does not exclude all polyps fibroid and other endometrial pathologies.

The present study evaluated the accuracy of saline infusionsonohysterography for the detection of intracavitary abnormality. Out of 50 cases 29 cases were premenopausal and 21 cases to be postmenopausal women. In our studyout of 50 cases $36 \%$ were found to be fibroids which was confirmed byhistopathology. In this 18 cases $12(24 \%)$ were premenopausal and $6(12 \%)$ werepost menopausal women. $14 \%$ women were found to have polyp in that 4 werepremenopausal women and 3 were postmenopausal women. $14 \%$ cases were foundto have diffuse hyperplasia. In out of 50 cases 2 cases(4\% ) were found to havecarcinoma. $4 \%$ of cases were of in secretory phase. And 1 cases of adenomyoma wasalso found in our study. Out of 50 cases in $14 \%$ of women the endometrial cavitydoes not have any obvious pathology.

In our study out of 50 cases we were not be able to do the procedure in 2cases due to cervical stenosis and cavity adhesions. We were able to dohistopathology analysis in most of the cases and the result correlated in $95 \%$ of thecases and in 2 cases the HPE does not correlate with our SIS findings. The 50 caseswere grouped into 2 category as premenopausal and postmenopausal women. Andfurther subdivided into endometrial and subendometrial pathology.in endometrialpathology it was further divided in to focal cases and diffuse cases.TVS is an inexpensive, non invasive and convenient way to directly visualisethe endometrial cavity. Therefore it is recommended as a 1st line of diagnostic toolfor assessing uterine pathology in premenopausal and post menopausal womenpresenting with AUB.

Since its introduction in the mid 1980s, TVS has become the standard way toimagine the female pelvis and served as important adjunct to radiologist \&sonologist. The endometrium of the ovulating reproductive age woman fluctuates insingle layer thickness from $2 \mathrm{~mm}$ in the early follicular phase to $6 \mathrm{~mm}$ in the lutealphase.

The correct method to measure the endometrial thickness is the sum of twoadjacent layers of endometrium,and the measurement is called as endometrial echocomplex(EEC). The EEC in the menstrual phase is $4 \mathrm{~mm}$ and up to $12 \mathrm{~mm}$ in the lutealphase. In our study we have taken the cut off level of $8 \mathrm{~mm}$ of ET for evaluatingendometrial pathologies in saline infused sonohysterography.It is difficult to define the exact cause of abnormal or irregular uterinebleeding in pre and post menopausal women. However pathologic conditions ofendometrium or myometrium are the causes. Anovulatory cycles are a common causebut hyperplasia, polyps, sub mucous myomas and carcinoma are possible and are ofconcern to the patients.

Saline infusion sonohysterography is a technique in which a catheter is placedinto the endometrial cavity and sterile saline is instilled to separate the walls ofendometrium.In 1993, a study by parson et al in the journal of clinical ultrasoundtermed the technique sonohysterography. this technique has be known by manynames SHG, Hysterosonography, SIS, TVS with fluid contrast augmentation andsaline contrast sonohysterography.

A catheter ( infant feeding tube of size 8 ) is placed in uterine cavity throughcervical os and sterile saline is injected into the endometrial canal which distends thecavity, and the uterine wall is separated . The anechoic fluid is then juxtaposedagainst the echogenic endometrium giving the accurate details of the cavity wall. Acomplete evaluation of the endometrial cavity is performed in both the coronal andsagittal planes. Doppler evaluation can be quite helpful for distinguishing blood clotsfrom polypoid lesions.

SIS can distinguish focal lesions from diffuse endometrial thickening. Polypsare focal lesions. TVS cannot distinguish endometrial hyperplasia from benign polypbecause both the condition can cause thickening of the endometrium which appear ashyperechoic and can contain cystic spaces. In SIS hyperplasia can appear as diffusethickening of endometrium although it can occasionally appear as a focal area ofendometrial thickening.

In a study by Jorizzo et al on endometrial hyperplasia,cyst were seen in 57\% of patients and concomitant endometrial polyp were found in $26 \%$ of patient.In a study by Dubinsky et al of 28 women with diffuse thickening ofendometrium, all 28 had either a secretory or proliferative endometrium at biopsy.This underscores the importance of the timing of SIS in menstruating women, theprocedure should be performed after the cessation of menses, ideally on day 4,5,6 ofthe menstrual cycle.

Endometrial hyperplasia is increased to about $1.3 \%-20 \%$ in tamoxifen treatedwomen.SIS and TVS have been recommended as tools for evaluating these women.

Fong et al evaluated asymptomatic post-menopausal women being treatedwith tamoxifen and found endometrial abnormalities in $40 \%$ of their studygroup.TVS had a sensitivity of $85 \%$ and specificity of $56 \%$ whereas SIS had asensitivity of $90 \%$ and a specificity of $79 \%$.

Tepper et al prospectively evaluated asymptomatic women with a history ofbreast cancer and tamoxifen therapy who had a thickened endometrium $>8 \mathrm{~mm}$ onTVS. The incidence of endometrial abnormalities in the study group was $32 \%$. 
A study by Hann et al evaluated 46 sonohysterograms in patients whoreceived tamoxifen for a mean of 2.6 years.SIS revealed endometrial polyps in $62 \%$ of patients; $12 \%$ had a thickened endometrium,and $8 \%$ had subendometrial cysts.63\% of sonohysterograms with prior negative endometrial biopsy results hadendometrial abnormalities including 10 polyps.They also found that in $14 \%$ ofcases,the finding of a normal endometrium on SIS allowed these patients to avoidfurther intervention.

De kroon et al in meta analysisreviwed 16 studies compromising 877procedures to determine the diagnostic accuracy of SIS in perimenopausal womenwith AUB and comparing it with hysteroscopy with or without HPE or hysterectomy.And found sensitivity of SIS for evaluating the uterine cavity was 0.95 and pooledspecificity was 0.88 and the sonographic procedure was successful in $86.5 \%$ of thepostmenopausal women and $95 \%$ of premenopausal women.

Laifernarinsl et al ( transvaginal saline hysterosonography- characteristicsdistinguishing malignant and various being conditions) studied 63 SIS withhistological confirmation. They found 26 polyp, 16 submucosal myomas, 3endometrial CA. 15 SIS revealed no abnormality and in 2 cases revealed both polypand fibroid.which slightly correlated with my study.

Reddi rani et al studied 52 patients in which $92 \%$ were postmenopausal and $8 \%$ were premenopausal menorrhagia was the comment symptoms and the mostcommon findings wasmyomas. The over all sensitivity and specificity whencorrelated with intra operative hysterectomy findings and HPE were 66\% and 88\% for TVS and $82 \%$ and $95 \%$ for SIS and concluded SIS is simple highly sensitive andspecific technique to detect intrauterine pathology in the evalution of AUB.

F.P.G. Leone et al did a comparative study of SIS and endometrial samplingand hysteroscopic endometrial biopsy in that 88 cases were premenopausal and 40cases were postmenopausal cases and concluded SIS as a tolerable as hysteroscopicbiopsy in thickened endometrium.

kelecsi et al found TVS,SIS and DH had sensitivity of $56 \%, 81 \%$ and $85 \%$ respectively and specificities of $72 \%, 100 \%$ and $100 \%$ respectively.

kramp et al found that TVS, SIS, and DH had sensitivities of $23 \%, 94 \%$ and $100 \%$ and specificities of $93 \%, 84 \%$ and $87 \%$ respectively.

\section{Complications of SIS:}

It does not have very serious complication. In our study many peopleexperienced mild pain ( which is bearable,that occurs when the catheter insertedreaches the funds of uterus or when saline distends the endometrial cavity). Onepatient had experienced pelvic inflammatory diseases but it is very rare complication.And others complications like dizziness or nausea can also occur in SIS but in ourstudy we did not experience this kind of complication.

\section{Summary}

Ultrasonography plays a key role in screening and diagnostic triage foruterine abnormalities. TVS is often the first imaging test under taken for evaluationof the uterus in women with AUB. TVS is used to identify mural abnormalities suchas fibroids and adenomyosis and screening for thickened endometrium.Saline infused sonohysterography is a powerful tool for evaluatingendometrial cavity for focal abnormalities such as polyp or submucosal fibroids. SISallows accurate detection of focal lesions. Our study confirms that SIS is very safe,cost effective, easy.Can be done as outpatient procedure for evaluating endometrial pathologies.And it can be included in any standard protocol flowchart in management of AUB.Our study well correlated with the histopathology findings.

\section{Conclusion}

Saline infused sonohysterography is safe,well tolerated, accurate, cost effectiveand easy to perform investigation, acceptable to patient as it is done as an outpatient procedure.It is highly sensitive in diagnosing intracavitary uterine endometrial pathologiesby comparing with histopathological results.SIS can be considered as initial investigation in patients with abnormal uterinebleeding and in differentiating focal and diffuse endometrial lesions.

\section{References}

[1]. Parsons AK, Lense JJ. Sonohysterography for endometrial abnormalities: preliminary results. J Clin Ultrasound 1993; 21:87.

[2]. Syrop CH, Sahakian V. Transvaginal sonographic detection of endometrial polypswith fluid contrast augmentation. Obstet Gynecology1992; 79:1041.

[3]. American College of Obstetricians and Gynecologists. ACOG TechnologyAssessment in Obstetrics and Gynecology No. 5: sonohysterography. Obstet\&Gynecology 2008; 112:1467.

[4]. La Sala GB, Blasi I, Gallinelli A, et al. Diagnostic accuracy of sonohysterographyand transvaginal sonography as compared with hysteroscopy and endometrial biopsy:a prospective study. Minerva Ginecol 2011; 63:421.

[5]. Kamel HS, Darwish AM, Mohamed SA. Comparison of transvaginalultrasonography and vaginal sonohysterography in the detection of endometrialpolyps.ActaObstetGynecolScand 2000; 79:60

[6]. Epstein E, Ramirez A, Skoog L, Valentin L. Transvaginal sonography, saline contrastsonohysterography and hysteroscopy for the investigation of women withpostmenopausal bleeding and endometrium > 5 mm. Ultrasound ObstetGynecol2001; 18:157. 
[7]. Schwärzler P, Concin H, Bösch H, et al. An evaluation of sonohysterography anddiagnostic hysteroscopy for the assessment of intrauterine pathology. UltrasoundObstetGynecol 1998; 11:337.

[8]. Soares SR, Barbosa dos Reis MM, Camargos AF. Diagnostic accuracy ofsonohysterography, transvaginal sonography, and hysterosalpingography inpatients with uterine cavity diseases.FertilSteril 2000; 73:406.

[9]. de Kroon CD, Jansen FW, Louwé LA, et al. Technology assessment of salinecontrast hysterosonography. Am J ObstetGynecol $2003 ; 188: 945$

[10]. Goldstein SR,ZeltserI,Horan CK, et al. Ultrasonography-based triage forperimenopausal patients with abnormal uterine bleeding. Am J ObstetGynecol1997; 177:102.

[11]. Darwish AM, Youssef AA. Screening sonohysterography in infertility.GynecolObstet Invest 1999; 48:43.

[12]. Luciano DE, Exacoustos C, Johns DA, Luciano AA. Can hysterosalpingo-contrastsonography replace hysterosalpingography in confirming tubal blockage afterhysteroscopic sterilization and in the evaluation of the uterus and tubes in infertilepatients? Am $\mathrm{J}$ ObstetGynecol 2011; 204:79.e1.

[13]. Hann LE, Gretz EM, Bach AM, Francis SM. Sonohysterography for evaluation ofthe endometrium in women treated with tamoxifen. AJR Am J Roentgenol 2001;177:337.

[14]. Schwartz LB, Snyder J, Horan C, et al. The use of transvaginal ultrasound andsaline infusion sonohysterography for the evaluation of asymptomaticpostmenopausal breast cancer patients on tamoxifen.Ultrasound ObstetGynecol1998; 11:48.

[15]. Wolman I, Groutz A, Gordon D, et al. Timing of sonohysterography inmenstruating women. GynecolObstet Invest 1999; $48: 254$

[16]. Exalto N, Stappers C, van Raamsdonk LA, Emanuel MH. Gel instillationsonohysterography: first experience with a new technique. FertilSteril 2007;87:152.

[17]. Davis PC, O'Neill MJ, Yoder IC, et al. Sonohysterographic findings of endometrialand subendometrial conditions. Radiographics 2002; 22:803.

[18]. Becker E Jr, Lev-Toaff AS, Kaufman EP, et al. The added value of transvaginalsonohysterography over transvaginal sonography alone in women with known orsuspected leiomyoma. J Ultrasound Med 2002; 21:237.

[19]. Alcázar JL, Errasti T, Zornoza A. Saline infusion sonohysterography inendometrial cancer: assessment of malignant cells dissemination risk. ActaObstetGynecolScand 2000; 79:321.

[20]. Dessole S, Rubattu G, Farina M, et al. Risks and usefulness of sonohysterographyin patients with endometrial carcinoma. Am J ObstetGynecol 2006; 194:362.

[21]. van Dongen H, de Kroon CD, van den Tillaart SA, et al. A randomised comparisonof vaginoscopic office hysteroscopy and saline infusion sonography: a patientcompliance study. BJOG 2008; 115:1232.

[22]. Epstein E, Ramirez A, Skoog L, Valentin L. Transvaginal sonography, salinecontrast sonohysterography and hysteroscopy for the investigation of women withpostmenopausal bleeding and endometrium > 5 mm. Ultrasound ObstetGynecol2001;18:157-162.

[23]. Dessole S, Farina M, Rubattu G, Cosmi E, Ambrosini G, Nardelli G-B. Sideeffects and complications of sonohysterosalpingography.FertilSteril2003;80:620-24.

[24]. Syrop CH, Sahakian V. Transvaginal sonographic detection of endometrial polypswith fluid contrast augmentation. ObstetGynecol 1992;79:1041-43.

[25]. Caspi B, Appelman Z, Goldsmith R, Ashkenazi M, Haruvy Y, Hagay Z. The brightedges of the endometrial polyp. Ultrasound ObstetGynecol 2000;15:327-30.

[26]. Cicinelli E, Romano F, Anastasio PS, Blasi N, Parisi C. Sonohysterography versushysteroscopy in the diagnosis of endouterine polyps. GynecolObstet Invest 1994;38:266-71.

[27]. BronzL,SuterT,RuscaThe value of transvaginal sonography with and withoutsaline instillation in the diagnosis of uterine pathology in pre- and postmenopausalwomen with abnormal bleeding/ suspect sonographic findings. UltrasoundObstetGynecol 1997;9:53-58.

[28]. Fleischer AC, Shappell HW. Color Doppler sonohysterography of endometrialpolyps and submucosal fibroids. J Ultrasound Med 2003;22:601-04.

[29]. Hann LE, Gretz EM, Bach AM, Francis SM. Sonohysterography for evaluation ofthe endometrium in women treated with tamoxifen. AJR 2001;177:337-42.

\section{Ix. Legends}
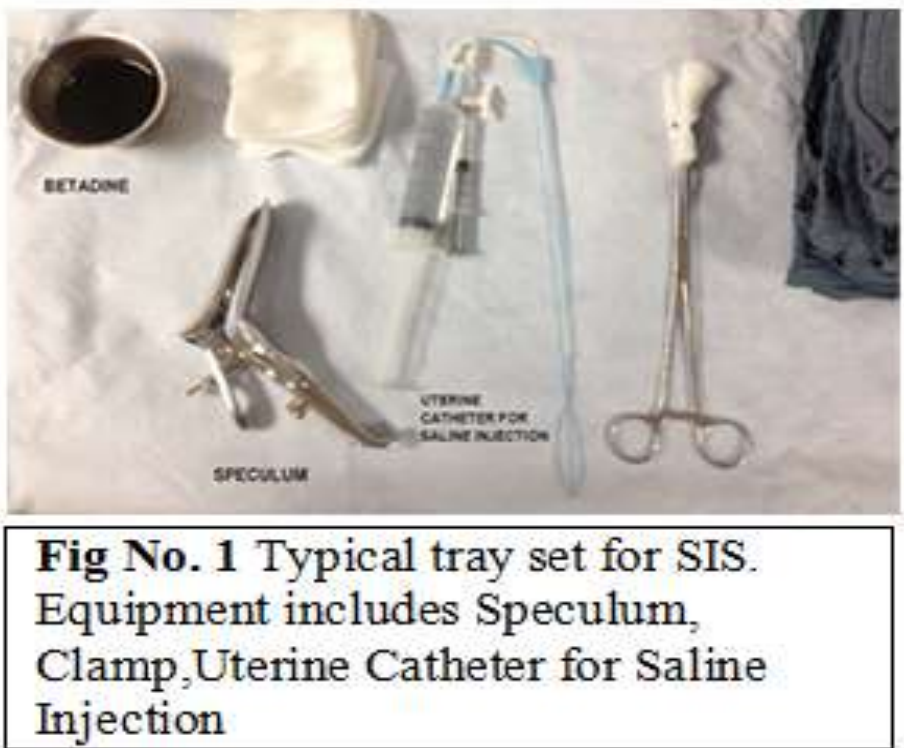


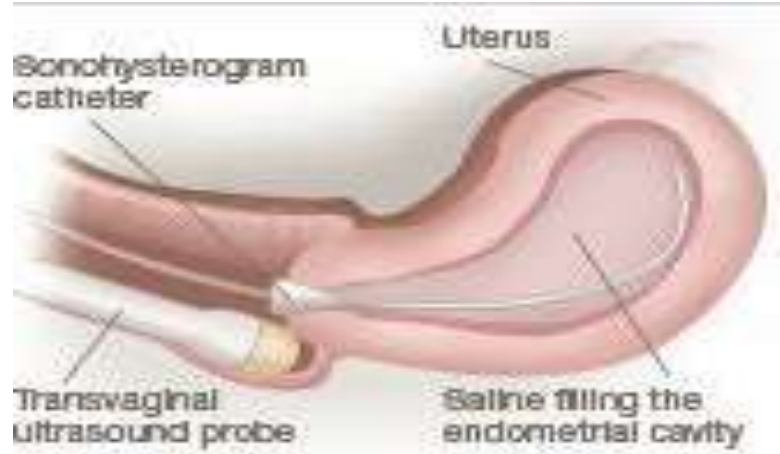

Fig No. 2 Sonohysterography Procedure

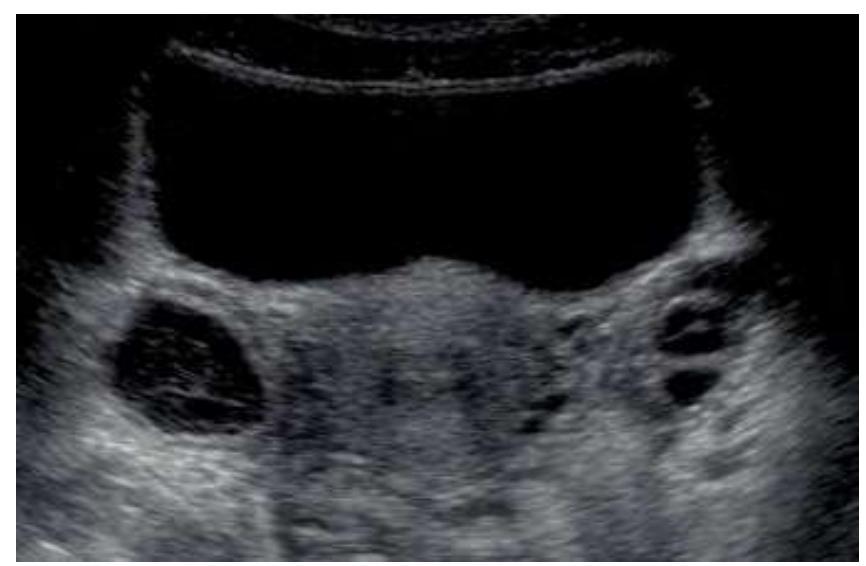

Fig No 3 Ultrasonography of lower abdomen showing normal anatomy of uterus

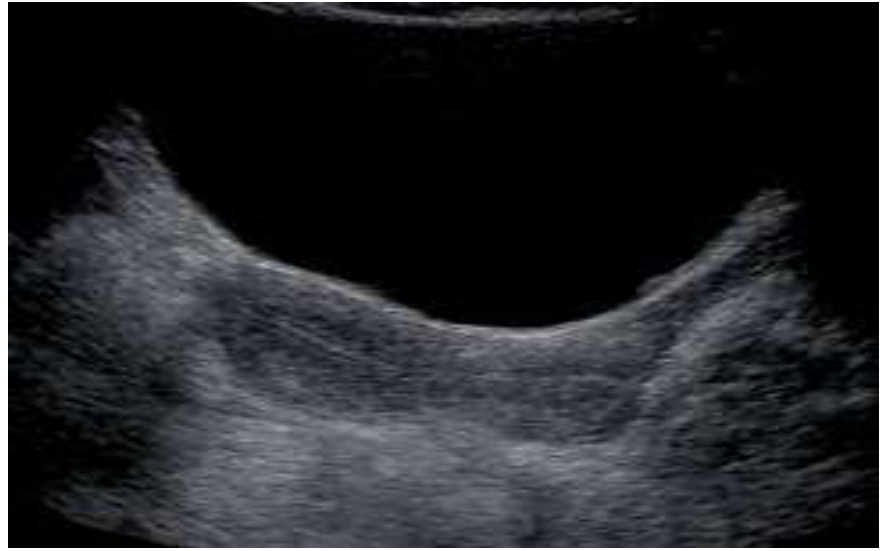

Fig No 4 Ultrasonography of the uterus in Sagittal plane

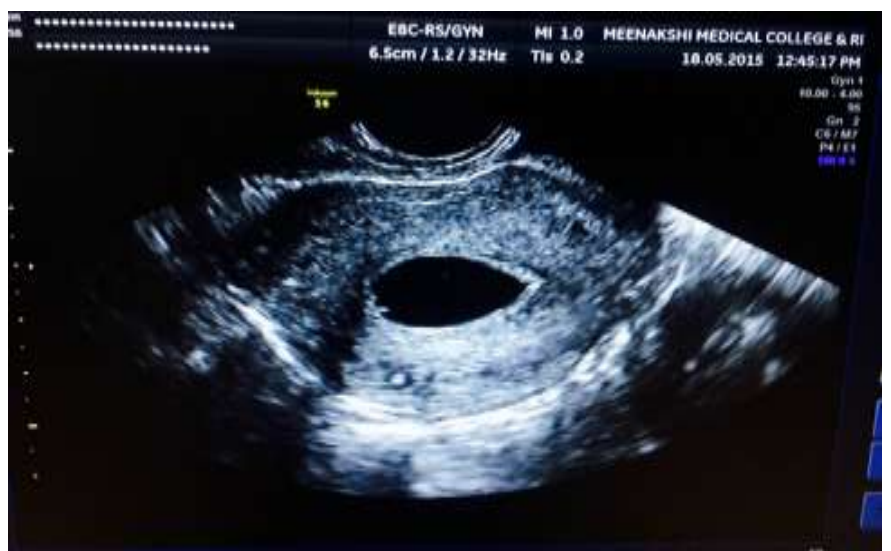

Fig No 5 SIS showing normal uterine cavity 


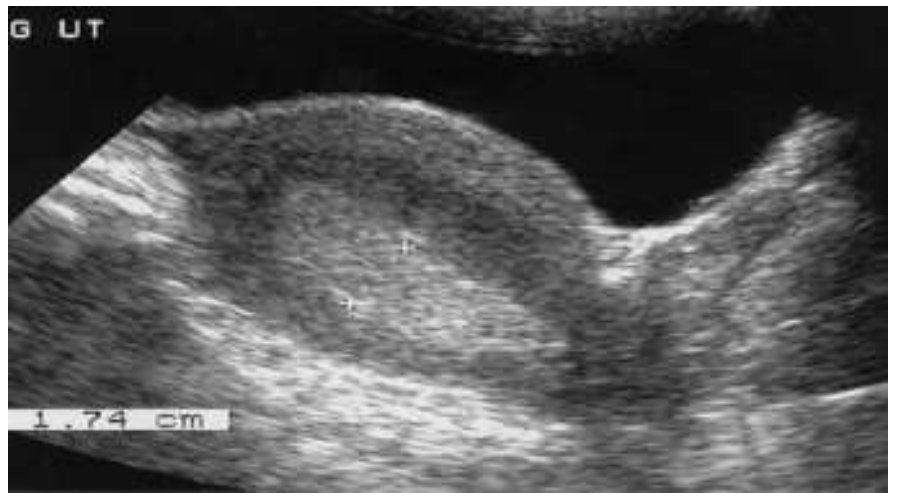

Fig No 6. ultrasound abdomen with thickened endometrium

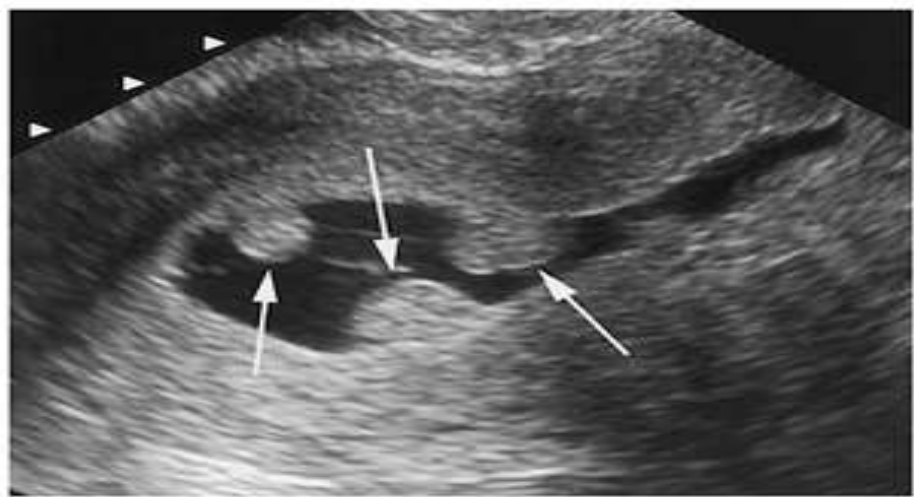

Fig No 7 saline infusion sonohysterography of endometrial cavityshowing multiple echogenic polyp.

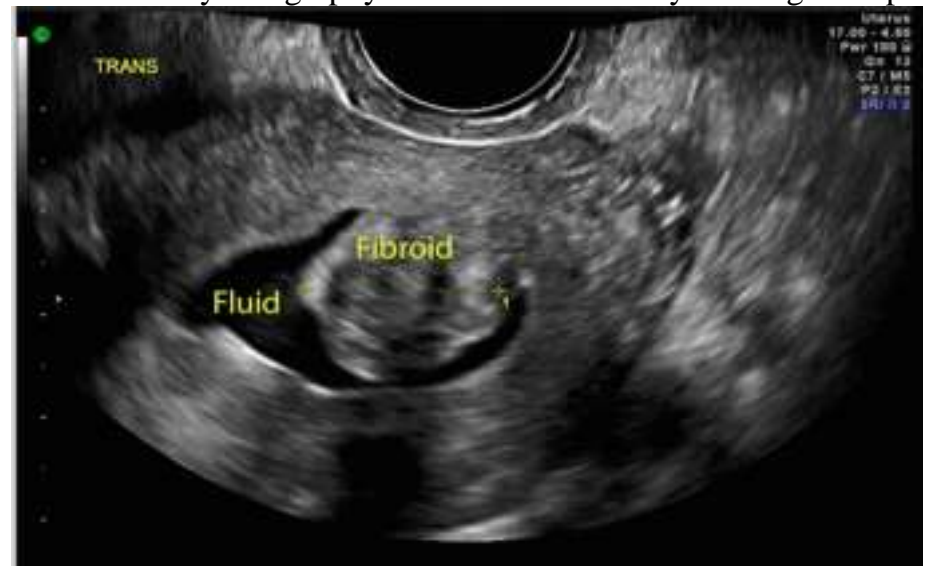

Fig No 8 saline infusion sonohysterography of endometrial cavity with large hypo echoic fibroid

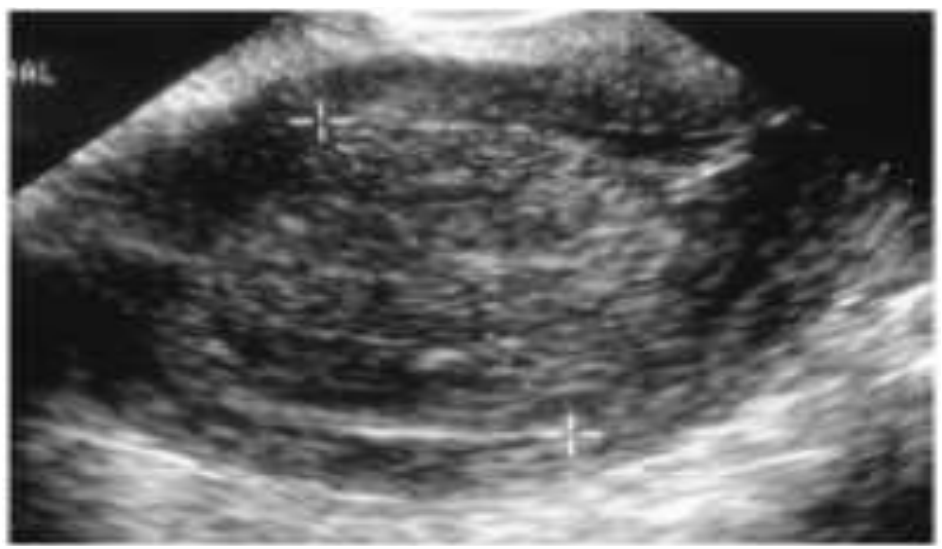

Fig No 9 TVS before saline infusion showing inhomogeneous thickened endometrium 


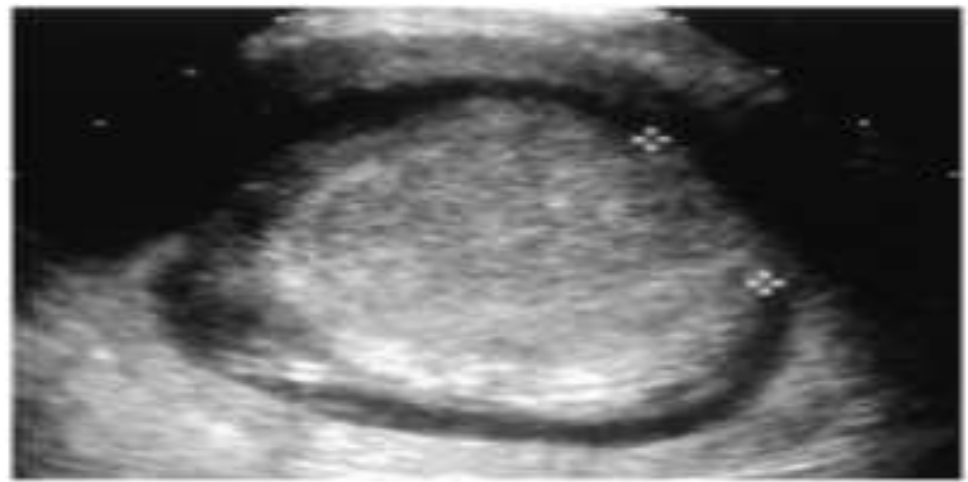

Fig No 10 TVS after saline infusion showing large diffuse mass

Histopathalogy examination slides:

Biopsy slide with hyperplasia:

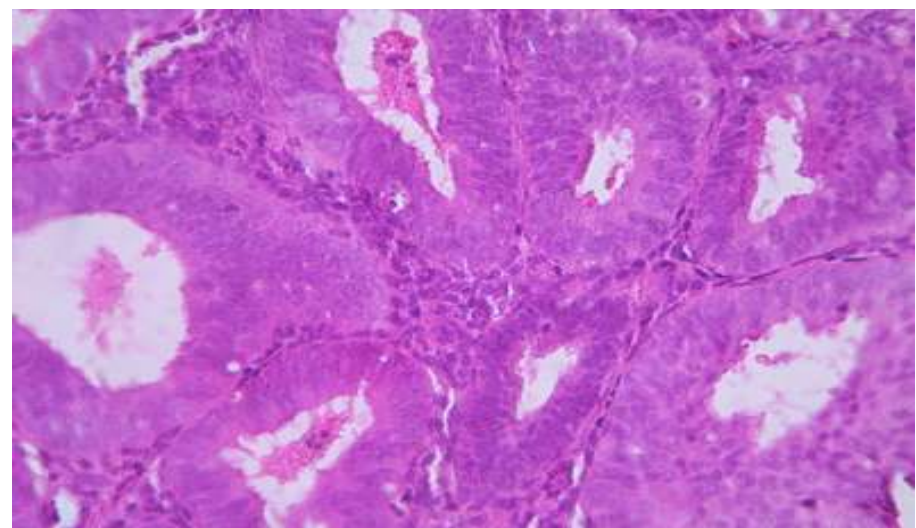

Fig No 11 Microscopic appearance of endometrium with hyperplasia

Biopsy Slide With Leiomyoma:

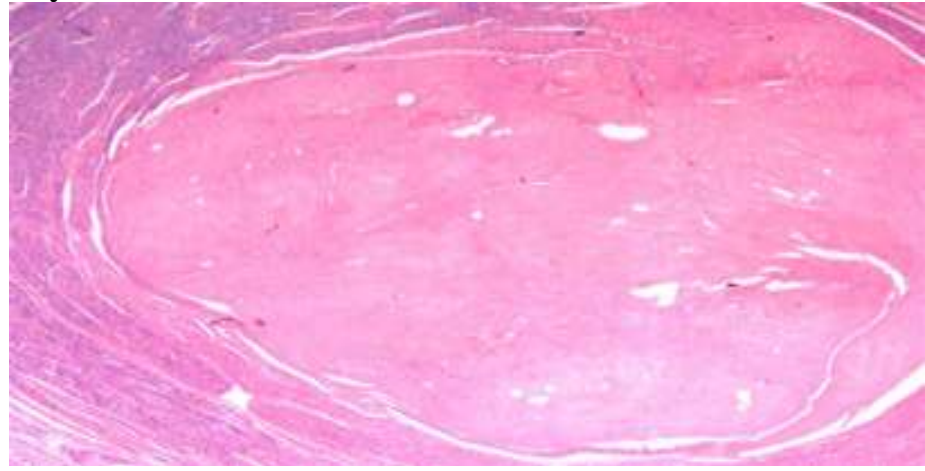

Fig No 12 microscopic appearance showing endometrial leiomyoma whorled fascicles of smooth muscle cells separated by a fibrovascular stroma

Biopsy slide with endometrial carcinoma:

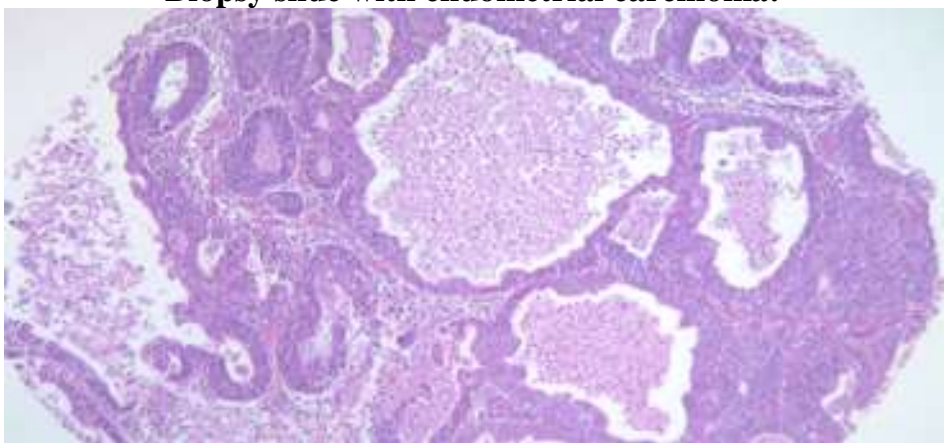

Fig No 13 Microscopic appearance of endometrium with carcinoma 


\section{Biopsy slide with endometrial polyp:}

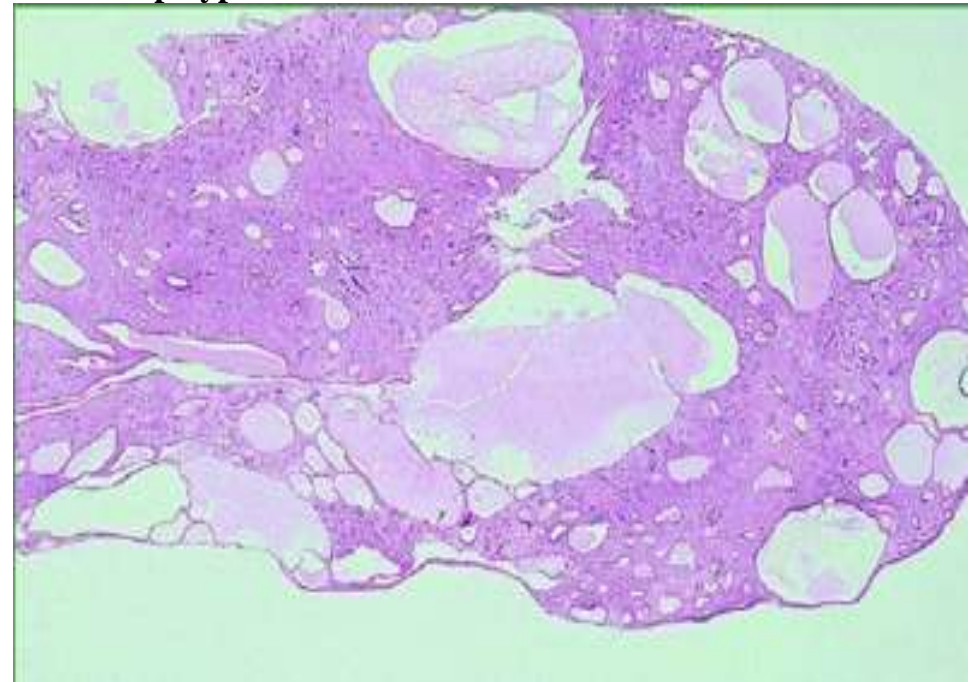

Fig No. 14 Endometiral polyp ( low power) showing mystically dilatedglands of various sizes and shapes.

\section{Biopsy slide with endometrial polyp:}

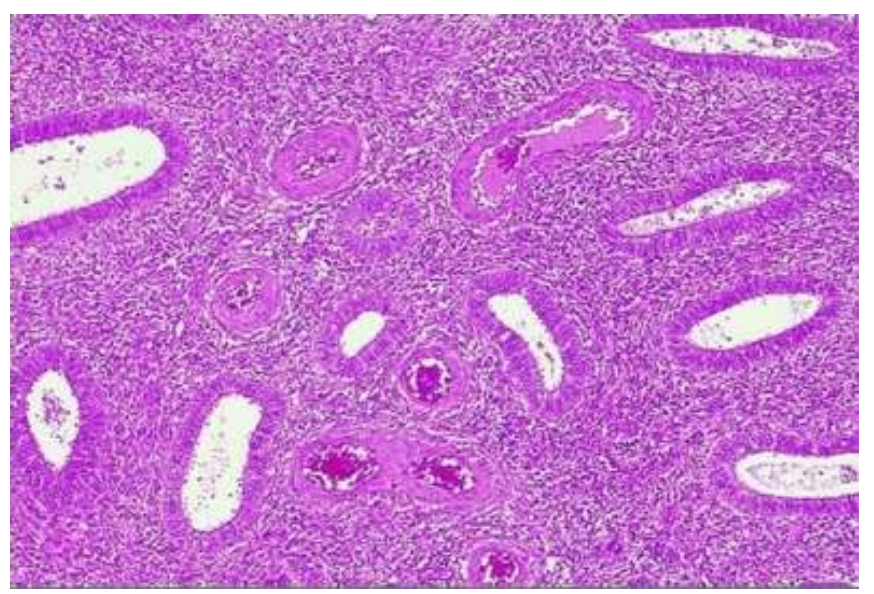

Fig No. 15Endometrial polyp (high power) characteristic features ofthick walled blood vessels in a fibrous core. 